\title{
The roles of binding site arrangement and combinatorial targeting in microRNA repression of gene expression Lawrence S Hon and Zemin Zhang
}

Address: Department of Bioinformatics, Genentech Inc., 1 DNA Way, South San Francisco, CA 94080, USA.

Correspondence: Zemin Zhang. Email: zhang.zemin@gene.com

Published: 14 August 2007

Genome Biology 2007, 8:RI66 (doi:I0.1 I86/gb-2007-8-8-r I66)

The electronic version of this article is the complete one and can be found online at http://genomebiology.com/2007/8/8/R I66
Received: 18 June 2007

Revised: 30 July 2007

Accepted: 14 August 2007

(c) 2007 Hon and Zhang; licensee BioMed Central Ltd.

This is an open access article distributed under the terms of the Creative Commons Attribution License (http://creativecommons.org/licenses/by/2.0), which permits unrestricted use, distribution, and reproduction in any medium, provided the original work is properly cited.

\begin{abstract}
Background: MicroRNAs (miRNAs) are small noncoding RNAs that bind mRNA target transcripts and repress gene expression. They have been implicated in multiple diseases, such as cancer, but the mechanisms of this involvement are not well understood. Given the complexity and degree of interactions between miRNAs and target genes, understanding how miRNAs achieve their specificity is important to understanding miRNA function and identifying their role in disease.

Results: Here we report factors that influence miRNA regulation by considering the effects of both single and multiple miRNAs targeting human genes. In the case of single miRNA targeting, we developed a metric that integrates miRNA and mRNA expression data to calculate how changes in miRNA expression affect target mRNA expression. Using the metric, our global analysis shows that the repression of a given miRNA on a target mRNA is modulated by 3' untranslated region length, the number of target sites, and the distance between a pair of binding sites. Additionally, we show that some miRNAs preferentially repress transcripts with longer CTG repeats, suggesting a possible role for miRNAs in repeat expansion disorders such as myotonic dystrophy. We also examine the large class of genes targeted by multiple miRNAs and show that specific types of genes are progressively more enriched as the number of targeting miRNAs increases. Expression microarray data further show that these highly targeted genes are downregulated relative to genes targeted by few miRNAs, which suggests that highly targeted genes are tightly regulated and that their dysregulation may lead to disease. In support of this idea, cancer genes are strongly enriched among highly targeted genes.
\end{abstract}

Conclusion: Our data show that the rules governing miRNA targeting are complex, but that understanding the mechanisms that drive such control can uncover miRNAs' role in disease. Our study suggests that the number and arrangement of miRNA recognition sites can influence the degree and specificity of miRNA-mediated gene repression.

\section{Background}

MicroRNAs (miRNAs) are small noncoding RNAs that repress gene expression by binding mRNA target transcripts, causing translational repression or mRNA degradation. Currently, 475 human miRNAs have been annotated in the miRNA registry [1], with over 1,000 miRNAs predicted to 
exist in human [2]. They are predicted to target one-third of all genes in the genome, where each miRNA is expected to target around 200 transcripts. Given the large number of miRNAs and potential targets, miRNAs may play a key regulatory role in many biological processes.

The biogenesis of miRNAs involves a core set of proteins to convert the longer primary transcript into the mature, approximately 22 bp miRNA [3,4]. At the DNA level, miRNAs are commonly found within introns of other genes, but others exist independently, transcribed as miRNA genes. In a few cases they are clustered together in a polycistron, as in the case of mir-17-92 [5]. Upon transcription, the primary miRNA is processed by Drosha, an RNA III endonuclease, to yield an approximately $70 \mathrm{bp}$ precursor miRNA [6]. The precursor miRNA is, in turn, exported from the nucleus to the cytoplasm by exportin $5[7,8]$. The enzyme Dicer then cleaves the precursor miRNA to yield a double-stranded mature product, from which one strand, the mature miRNA, is incorporated into the RNA-induced silencing complex (RISC) $[9,10]$.

Although miRNAs are believed to regulate their targets primarily through translational inhibition, there is increasing evidence that miRNAs can also influence the abundance of target mRNAs [11]. In both mammalian and Drosophila systems, miRNAs have been shown to accelerate target mRNA degradation through the normal pathway of deadenylation [12-14], consequently decreasing target mRNA abundance. In fact, Lim et al. [15] showed that transfection of mir-1 and mir124 into HeLa cells caused the downregulation of a significant number of genes at the transcriptional level. In another study, Krutzfeldt et al. [16] reported that knockdown of mir-122 using their 'antagomir' approach resulted in changes in mRNA expression for a large number of genes. The effects of miRNA-mediated mRNA degradation are moderate [12] but, nonetheless, these reports show that expression microarrays can capture the effects of miRNA repression on target genes.

Misexpression of miRNAs or improper repression of their targets can have diverse and unexpected effects. For example, a mutation in the myostatin gene (GDF8) in Texel sheep creates a miRNA binding site responsive to mir-1 and mir-206 that gives the sheep their meatiness [17]. In human cancer, various miRNAs are amplified or deleted [18], or otherwise have aberrant expression, suggesting that they may behave as oncogenes or tumor suppressor genes (for reviews, see $[19,20])$. Lastly, miRNA expression patterns for a large set of miRNAs can classify human cancers, suggesting a possible underlying connection between miRNA expression and oncogenesis [21]. Given the complexity and degree of interactions between miRNAs and target genes, understanding how miRNAs achieve their specificity is important to understanding miRNA function and identifying their role in disease.
The rules that govern miRNA target specificity are not clear, but can, in principle, be divided into several levels. At the most basic level, the specific sequence that makes up a miRNA target site determines how well the miRNA binds to the site. One often proposed rule is that a conserved 'seed' match, consisting of bases 2-9 of the miRNA, is a reliable predictor of a miRNA-target interaction, which has been supported by mutation studies that showed that those base pairs are often sufficient for binding [22]. Many miRNA target prediction algorithms have, therefore, incorporated aspects of this rule in their predictions [22-25]. However, others question whether a seed match is either necessary or sufficient for miRNA repression: a recent paper showed that perfect base pair matching does not guarantee interaction between miRNA and target gene [26], and wobble G:U base pairs are often tolerated in target sites [27,28], highlighting the complexity of miRNA-target interactions. At the intermediate level, the configuration of miRNA target sites can affect the strength of a miRNA-target interaction. For example, Doench and Sharp [29] considered the effects of altering the spacing between two CXCR4 binding sites. In addition, Sætrom et al. [30] recently found a range of 13-35 bp between let-7 binding sites optimizes let-7 repression. Furthermore, target prediction algorithms in general give higher scores to interactions where the target gene contains multiple binding sites [22-25]. Despite the complexity of the rules that govern miRNA target specificity, experimental validation of these algorithms show that these methods are quite accurate and sensitive (approximately $80 \%$ in one study in Drosophila melanogaster [31]), supporting their use in large scale analyses.

In contrast to considering miRNA target specificity at the single miRNA-target interaction or binding site levels, another level of miRNA control may involve understanding how combinations of different miRNAs may work in concert to repress a target gene. This concept was borrowed from the study of transcription regulation, where it is well known that multiple transcription factors can regulate a target gene. One clue that multiple targeting is present in miRNA regulation as well was the observation that some genes are targeted by many different miRNAs [23,25,32]. Transfection experiments [23,29] have further shown that coexpressed miRNAs can repress a gene in a concentration-dependent manner. Finally, a study in fly and worm showed that target sites for different miRNAs are often simultaneously conserved, supporting the idea of combinatorial action by miRNAs [33]. However, the extent of this phenomenon and whether miRNAs can work in concert to repress a gene need further investigation.

In this paper, we investigate the factors that affect the degree and specificity of miRNA targeting by examining the effects of both single and multiple miRNAs targeting a gene. In the case of single miRNA targeting, we explore the relationship between features of miRNA target sites and level of repression of an mRNA using a large dataset with both miRNA and mRNA expression. To do this, we developed a relative 
expression (RE) metric that calculates the degree of repression of a target gene as a function of changes in the expression of a miRNA. While prior systematic genome-wide efforts used expression microarrays and in situ hybridization to study mRNA target expression profiles [31,34-36], we incorporate both miRNA and mRNA expression data in our method, which allows us to interrogate the effects of changes in miRNA expression on target gene expression across many samples. We focus on the trends that emerge when looking at large groups of interactions, since the relationship between miRNA and mRNA in an individual interaction can be obscured by factors that regulate that mRNA's expression, such as transcriptional and splicing regulation. The metric is used to measure the effects of various binding site characteristics on miRNA repression, including 3' untranslated region (UTR) length, number of binding sites, and the distance between binding sites.

We also describe an interesting relationship between the length of CTG repeats and miRNA repression, opening the possibility that miRNAs that bind CTG repeats may be involved in CTG repeat expansion disorders such as myotonic dystrophy type 1 (DM1). CTG repeat expansion mutations in the 3' UTR are known to play an important role in several diseases, including DM1, spinocerebellar ataxia type 8, and Huntington's disease-like 2, which are all members of a class of diseases described as dominant noncoding microsatellite expansion disorders [37]. Among CTG repeat expansion disorders, DM1 is the most prevalent, affecting $1 / 8,000$ adults, and its symptoms are multisystemic and variable, including myotonia (delayed relaxation of muscle), muscle loss, cardiac conduction defects, cataracts, insulin resistance, and mental retardation (for reviews, see [37-39]). DM1 is caused by a CTG repeat expansion mutation in the 3' UTR of the DMPK gene, with the most severe forms of the disease reaching thousands of repeats. Given that there are many unknowns in DM1 pathogenesis, a possible role of miRNAs in DM1 could enhance the overall understanding of the disease mechanism and thus provide new angles for therapeutic intervention.

Besides analyzing determinants of single miRNA targeting, we also examine genes that are targeted by multiple miRNAs and find that they are an unexpectedly large class of genes with strong enrichment for transcriptional regulators and nuclear factors. Expression microarray data show that these highly targeted genes are downregulated relative to genes targeted by few miRNAs, which suggests that highly targeted genes are tightly regulated and their dysregulation may lead to disease. In support of this idea, cancer genes are strongly enriched among highly targeted genes. Together, these genome-wide analyses show that the rules influencing miRNA targeting are complex, but that understanding the mechanisms that drive such control can uncover miRNAs' role in disease.

\section{Results \\ Single miRNA targeting}

We first investigated the effects of a single miRNA targeting a gene. Since we were interested in how highly expressed miRNAs could potentially repress a target gene more strongly, we exploited data from Lu et al. [21] and Ramaswamy et al. [40], containing 89 human tumor and normal samples (across 11 tissue types) for which both miRNA and mRNA expression data are available. To estimate the degree of repression (at the transcriptional level) resulting from a miRNA binding to a target transcript, we developed a RE metric, which relates changes in miRNA expression to changes in target mRNA expression (see Materials and methods for details). In summary, for a given miRNA-mRNA interaction, the RE of the interaction pair is the ratio of average mRNA expression for the one-half of samples with 'high' miRNA expression (group A), divided by the average mRNA expression for the one-half of samples with 'low' miRNA expression (group B). In interaction pairs with significant repression, the group A samples with high miRNA expression will have lower average gene expression than the group B samples with low miRNA expression, resulting in a lower RE. It is important to note that we focus on trends of RE values rather than a single absolute RE value, since the absolute $\mathrm{RE}$ value may be hard to interpret; $\mathrm{a}$ $\mathrm{RE}$ value of 1.0 may mean that the miRNA is not repressing the target gene, or it could also mean that the miRNA repression of the gene is counterbalanced by factors that promote activation of the gene. We used miRNA target predictions from the PicTar algorithm [23] to define miRNA-mRNA interactions. Unless otherwise specified, the following analyses use the Lu and PicTar data. Data composing the experiments can be found in the Additional data files.

We first asked if the 3' UTR length of a gene affects miRNA repression. To counteract the effects of differing numbers of binding sites, we considered only miRNA-mRNA interactions for which the mRNA was predicted to have only one target recognition site for that miRNA (but could contain binding sites predicted to be responsive to other miRNAs; Additional data file 1 illustrates the different analyses). The relationship between 3 ' UTR length and degree of repression by cognate miRNAs, as measured by the RE metric, is shown in Figure 1a. MiRNA-mRNA interactions containing genes with shorter 3 ' UTRs tend to have lower RE values (approximately 5-10\%), indicating stronger repression $\left(P=4.9 \times 10^{-4}\right.$ for lengths $<400$ versus lengths $>800$ ).

To assess whether the repression observed was reasonable, we performed two analyses. In the first analysis, we calculated the expected repression for the various 3' UTR lengths if the relationship between miRNA expression and target mRNA expression were removed. By randomizing samples considered to have high or low miRNA expression, we determined the expected RE value and error at each 3 ' UTR length and found expected RE values of approximately 1.o (Figure 1b), representing no repression. This showed that the changes 


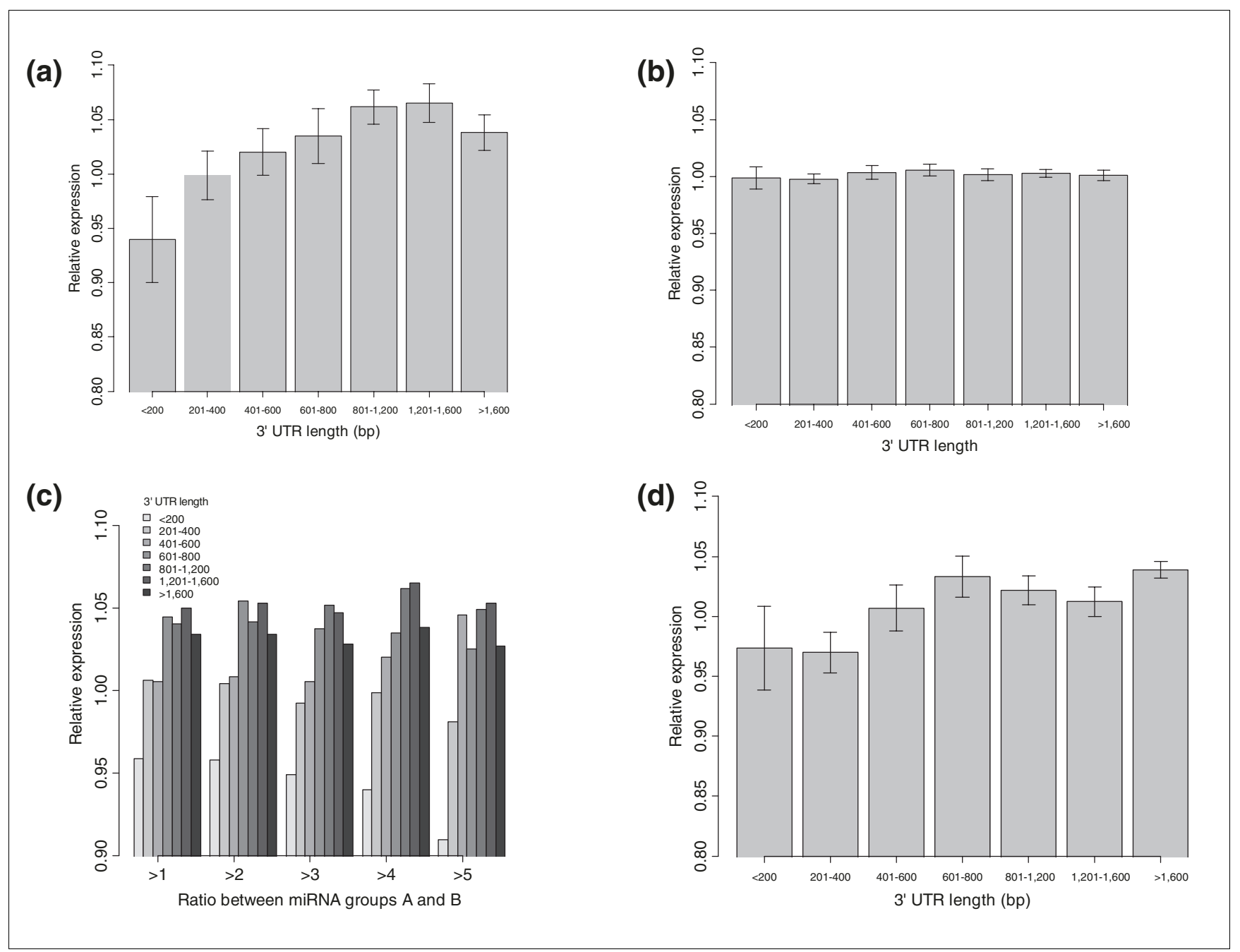

Figure I

Analysis of the relationship between shorter 3' UTRs and increased repression. The error bars for observed and expected data are based on the distribution of RE values and the distribution of the permutated data, respectively. (a) Shorter 3' UTRs in target genes are more strongly repressed by their predicted cognate miRNAs. (b) The expected RE values (computed using permutation testing) show minimal deviation from I.0, representing a lack of repression. (c) This trend is increasingly exaggerated when subsets of miRNAs containing larger expression ratios between groups $A$ and $B$ are used, especially in 3' UTRs shorter than 200 bp. (d) The same trend of increased repression in shorter 3' UTRs is observed using a different target prediction algorithm, rna22.

in RE values we observed were specifically due to miRNA repression. Repeating this permutation analysis on later experiments gave similar results (Figure 2). In the second analysis, we estimated the expected magnitude of transcriptional repression for a set of predicted target genes by analyzing an independent expression data set from Lim et al. [15], where they transfected miRNA into HeLa cells and measured the resulting changes in expression from a panel of genes (see Materials and methods). Using PicTar predicted targets or 3' UTRs containing 7-mer seeds, the largest average downregulation for a group of predicted targets within a given transfection experiment was only $2 \%$. If we ranked the targets by the degree of downregulation and took the subset of genes that were among the top $10 \%$ most downregulated, the maximum average downregulation for a subset for any experiment was
$15 \%$. This suggests that not many target genes are downregulated by more than $15 \%$. Since the experiment artificially introduces a large amount of miRNA to cells, and our approach reports average changes in expression across a set of samples, a 5-10\% change in expression for a group of predicted target genes represents a reasonable level of repression we might expect to see using our approach. These two analyses served to validate the use of relative expression on miRNA and mRNA expression data.

Next, we verified that the increased repression observed in shorter 3' UTRs was biologically significant and not due to artifacts in the data. First, to see if miRNAs with a larger range of expression might exhibit a larger range of target mRNA repression, we considered subsets of miRNAs that had 


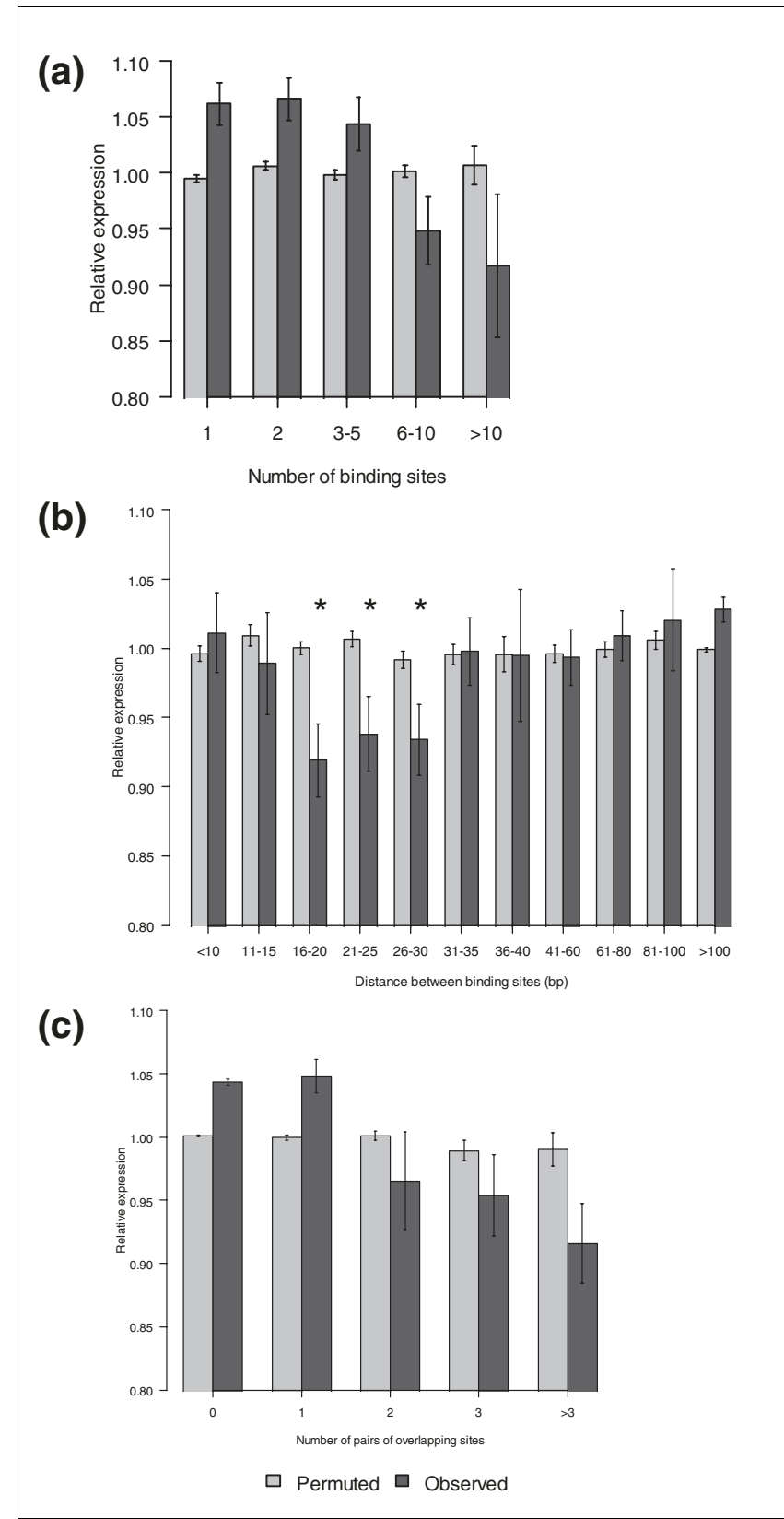

Figure 2

Analysis of site and gene features that affect miRNA repression. The observed values are shown in black; the expected values (computed using permutation testing) are shown in gray. The error bars for observed and expected data are based on the distribution of RE values and the distribution of the permutated data, respectively. (a) Target genes with more binding sites are more strongly repressed. (b) Pairs of binding sites targeted by the same miRNA that are between 16 and 30 bp apart (by start positions) have significantly increased repression (asterisks shown for emphasis). (c) Genes that have multiple pairs of extensively overlapping sites, defined to be two binding sites responsive to the same miRNA whose start positions are within 10 bp of each other, have increased repression.

differing ratios of expression between samples in group A versus samples in group B. As the minimum threshold of miRNA expression ratio was increased, the relative expression of genes with 3' UTRs shorter than 200 bp decreased (Figure 1c), suggesting that the RE metric benefits from greater variation in miRNA expression. Second, we considered if the result was an artifact of the miRNA target prediction algorithm used, for example, a subtle bias that would somehow preferentially identify interactions containing short 3' UTRs with low RE values. Since PicTar and other commonly used methods employ sequence conservation at the seed region as a major component of their prediction strategy, we therefore repeated the analysis using predictions from rna22 [27], a different approach that does not depend on conserved seed matches. Despite replacing the target predictions used, the same trend of greater repression found in shorter 3 ' UTRs was observed $\left(P=7.4 \times 10^{-7}\right.$ for lengths <400 versus lengths $>800$; Figure 1d). Last, we tested if the result could be recapitulated using an independent data set. We obtained matching miRNA and mRNA expression data for the NCI-6o set of cell lines (see Materials and methods) and repeated the experiment using these data. Again, shorter 3' UTRs tended to be more repressed $(P=0.0002$ for lengths $<400$ versus lengths $>800$ ). Thus, these results indicate that the increased repression of shorter 3 ' UTRs is not an artifact.

Given the confidence that we were observing a real increase in repression for shorter 3' UTRs, several explanations could account for this: first, a long 3' UTR might simply encode a complex environment in which other binding sites reside, so that the repression of the transcript by the original miRNA may be mediated by other factors; second, the probability of finding a conserved binding site increases with 3 ' UTR length, such that longer sequences are more likely to contain spurious sites that do not confer repression; or third, the repression could be a consequence of the physical layout of the transcript where it might be more difficult for a miRNA to find its target site within a longer 3' UTR. To further explore the final explanation, we asked if binding sites near the end of the 3' UTR might be more easily recognized by the miRNA machinery and, therefore, more likely to be repressed. We found that genes with binding sites near the end of the 3 ' UTR were more repressed $(P=0.0002$ for $<200 \mathrm{bp}$ from the end versus $>600 \mathrm{bp}$ from the end, and $P=0.001$ for $<400 \mathrm{bp}$ from the end versus $>800$ bp from the end), even when shorter $3^{\prime}$ UTRs (<400 bp) were removed (data not shown). Since the results might be based on a combination of all three explanations, these results are consistent with the notion that 3 ' UTR lengths vary for functional reasons, in this case because of miRNA binding relationships.

Next we examined the effect of multiple binding sites for a given miRNA on a transcript, since for a given miRNA some genes have many more target sites than others. To reduce effects of variation in mRNA expression between tissue types due to tissue-specific effectors such as transcription and splicing factors [41], which would obfuscate the effects of miRNA repression on mRNAs, we focused only on housekeeping genes defined by Eisenberg and Levanon [42]. This 
resulted in a list of 155 housekeeping genes for which mRNA expression data were available, with which we plotted the number of binding sites on a target gene for a given miRNA versus RE. Figure 2a shows that genes are more repressed as the number of binding sites increases $\left(P=4.2 \times 10^{-6}, n<5\right.$ versus $n \geq 5$ ). The trend remained if we used instead either NCI-6o expression data $\left(P=2.6 \times 10^{-7}\right.$; Additional data file $2 b)$ or Rna22 target predictions $(P=0.02$ for $n \leq 2$ versus $n>$ 2; Additional data file 2a). This result supports previous work describing a relationship between the number of binding sites and the degree of repression $[43,44]$. Together, the observations that both 3 ' UTR length and number of binding sites affect repression show that the strength of repression is dependent on the density of binding sites within a 3' UTR.

If the number of binding sites on a target gene affects the degree of repression, the physical distance between binding sites might also affect repression efficacy. We focused on genes with 3 ' UTRs shorter than 800 bp since we had observed greater repression among shorter 3 ' UTRs, using the idea that the interactions involving shorter 3 ' UTRs might be more reliable. Using the remaining genes, we examined all predicted interactions for which the target gene has two or more binding sites. For each pair of binding sites on a target gene responsive to a miRNA, we computed the distance between the 5 ' ends of the sites, where distances less than the length of the miRNA (approximately $22 \mathrm{bp}$ ) represent sites that overlap. Multiple pairs of nearby binding sites responsive to the same miRNA on a given target gene were treated independently and each assigned the RE value for the interaction. We found that binding site pairs with distances between 1630 bp were repressed by $5-10 \%$ (Figure $2 b$ ). Compared to binding site pairs with either shorter or longer distances, RE values for pairs of binding sites between 16-30 bp were significantly different $\left(P=2.2 \times 10^{-5}\right.$ for $x \leq 15$ versus $16 \leq x \leq 30$, and $P=4.9 \times 10^{-5}$ for $x>30$ versus $16 \leq x \leq 30$ ). It appears that binding sites with distances of $16-30$ bp are in a 'sweet spot' that maximizes repression. Two sites with significant overlap might result in steric hindrance, where only one miRNA could access the two sites at a time, resulting in increased RE values. On the other hand, two sites that are farther apart might experience lower site availability due to the lower concentration of binding sites.

Additional data and recently published literature support this observation. First, similar results were observed when considering the subset of predicted interactions containing exactly two binding sites (data not shown). Second, we performed the analysis on the NCI-6o data using all genes and found increased repression for pairs of binding sites between 16 and 21 bp apart $\left(P=9 \times 10^{-4}\right.$ for $x \leq 15$ versus $16 \leq x \leq 21$ and $P=2.3 \times 10^{-8}$ for $x>21$ versus $16 \leq x \leq 21$; Additional data file 2c); though we are not certain why a smaller range of distances shows increased repression, the overlap between the results from the NCI-6o and Lu data emphasizes the repeatability of the result. Third, we verified that the result was not an artifact of binning by using a $10 \mathrm{bp}$ sliding window of distances to identify regions that maximized repression. In both data sets, the most significant distances between binding sites occur between 16 and 30 bp apart (data not shown). Fourth, these results are consistent with transfection experiments in HeLa cells measuring translational repression, where it was shown that binding sites between 4 bp apart and 4 bp of overlap were more repressed than bindings sites with greater overlap, though the effect of larger distances between binding sites was not examined [29]. Additionally, Sætrom et al. [30] recently found maximal let-7 repression of reporter gene constructs where pairs of let-7 target sites are at distances between 13 and $35 \mathrm{bp}$, a range similar to our results. Together, these various data support the importance of the distance between sites for repression.

While pairs of extensively overlapping binding sites were shown to have decreased repression, we also saw a disproportionate number of highly overlapping binding sites genomewide (Figure 3). To investigate this further, we analyzed miRNA-mRNA interactions with multiple pairs of extensively overlapping sites, where a pair of extensively overlapping sites is defined to be a pair of binding sites with start positions less than 10 bp apart. Within this dataset, interactions had up to seven pairs of extensively overlapping sites. When we calculated RE as a function of number of pairs of extensively overlapping sites, we saw greater repression among genes with more pairs of extensively overlapping sites (Figure 2c; $P$ $=3.8 \times 10^{-8}$ for $n<3$ versus $n \geq 3$ ). Using NCI-6o data, interactions containing pairs of extensively overlapping sites also tended to have lower RE values compared to those that had none $\left(P=2 \times 10^{-5}\right)$. Therefore, although a single pair of strongly overlapping binding sites had reduced repression, this reduction can be counteracted by the presence of many binding sites.

To understand how multiple pairs of extensively overlapping sites could induce greater repression, we examined individual miRNA-mRNA interactions. We found that, in many cases, a gene could embed multiple pairs of extensively overlapping sites within a small region of its $3^{\prime}$ UTR via repetitive sequence. For example, $S N F 1 L K\left(N M \_173354\right)$ is predicted to contain six mir-15b target seed sites within a $21 \mathrm{bp}$ window. Figure 4a shows how this is possible: mir-15b's seed region contains multiple CTG repeats, which would be potentially responsive to the seven CTG repeats on the 3 ' UTR in six different locations, creating five out of the seven total pairs of extensively overlapping sites. Given the large number of potential binding sites in a localized region of 3 ' UTR, the increased repression of multiple pairs of binding sites can be explained by having more binding sites available to bind to, which in turn means a greater probability of binding and thus repression. In contrast, the reduced repression of a single pair of overlapping binding sites seen in Figure $2 \mathrm{~b}$ potentially reflects the penalty of two miRNA molecules physically 


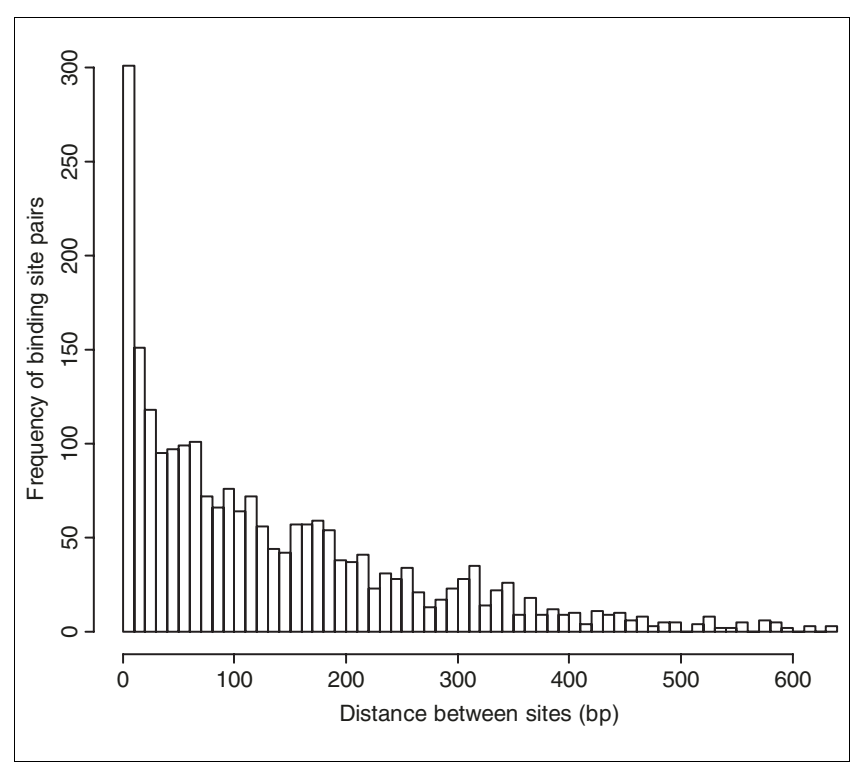

Figure 3

Frequency of pairs of binding sites targeted by the same miRNAs separated by a given distance. The distance between a pair of binding sites is calculated from the $5^{\prime}$ ends of the target sites relative to the mRNA. A disproportionate number of binding site pairs are within $10 \mathrm{bp}$ of each other.

blocked from binding both sites, which can be overcome by having more pairs of extensively overlapping sites.

Given that CTG repeat-containing 3' UTRs might be strongly repressed by miRNAs, we examined if CTG repeat-binding miRNAs also exhibited a correlation between number of pairs of extensively overlapping sites and repression. First we identified miRNAs with CAG repeats in their seed region besides mir-15b; these included mirs-15a, -16, -103, -107, -195, and 214 (Figure 4b). Then, for each CTG repeat-binding miRNA, RE values were calculated for target genes containing extensively overlapping pairs of sites responsive to that miRNA. Figure $4 \mathrm{c}$ shows that repression generally increases as the number of pairs of extensively overlapping sites increases, with the exception of mir-214, whose seed region does not contain a full complement of CAG repeats, and mir-15b, which has few targets $(\leq 3)$ predicted to have six or more pairs of extensively overlapping sites. In particular, mirs-107, -103, and -15 a show a strong relationship between the degree of repression and pairs of extensively overlapping sites.

Finally, we asked if CTG repeat-binding miRNAs repress wild-type $D M P K$, as a precondition to the possibility that miRNAs might be involved in the repression of mutant DMPK in DM1. All seven miRNAs were associated with DMPK repression using the RE metric $(P=0.02$ by binomial test), with mir-107 and mir-103 repressing DMPK among the most at about $15 \%$ (Figure 4d). By contrast, predicted targets of the CTG repeat-binding miRNAs that contain no overlapping pairs of sites show no overall repression (Figure 4d). These data provide a preliminary validation to our postulation that miRNA repression may be involved in DM1 pathogenesis (discussed later).

\section{Multiple miRNA targeting}

The analyses above considered the effects of single miRNAs on their target genes; we next explored the effects of multiple miRNAs targeting the same gene. Using the target predictions from PicTar [23], we identified 6,123 human genes that are predicted to be targets of one or more miRNAs. On average, these genes are targeted by 7.3 miRNAs, with some genes predicted to have as many as 65 different miRNAs targeting them. It was unlikely to observe such a large number of different miRNAs targeting a single gene by chance, since the expected number of miRNAs predicted to target a gene is approximately $2(44,853$ miRNA-mRNA interactions spread over 18,567 genes). In fact, 755 genes were targeted by more than 15 distinct miRNAs (top 50 shown in Table 1, consisting of genes targeted by $\geq 39$ miRNAs). The enrichment for genes targeted by multiple miRNAs has been discussed elsewhere $[25,32]$, but multiply-targeted genes as a gene class have not been fully explored.

To test whether the existence of so many highly targeted genes could occur by chance, we computed the expected number of genes targeted by more than 15 miRNAs using permuted data, where we scrambled the miRNA-gene relationships while keeping the number of targets per miRNA and miRNA family characteristics intact (see Materials and methods for details). On average, only 255 genes were expected to be targeted by more than 15 miRNAs (Figure $5 \mathrm{a} ; P<0.001$ ). Repeating the analysis using target predictions from TargetScanS [24] and miRanda [25], similarly large differences between observed and expected number of highly targeted genes were found (Figure 5a), controlling for the possibility that the existence of highly targeted genes is due to algorithmbased biases.

The enrichment of highly targeted genes suggested that this could be a unique set of genes having common function. To test this, we performed a Gene Ontology (GO) analysis of genes targeted by more than 30 miRNAs. Table 2 shows GO categories that are the most significant in overrepresentation of these highly targeted genes. About one-third of these genes are involved in transcriptional regulation $\left(P=4 \times 10^{-12}\right)$, and nearly half encode nuclear proteins $\left(P=2 \times 10^{-15}\right)$, shown in Figure $5 \mathrm{~b}$. The fact that many miRNAs target the same transcriptional regulators and other nuclear genes suggests that an important means of gene regulation by miRNAs involves the direct repression of these target genes in order to trigger downstream effects. Additionally, 25\% of genes are involved in developmental processes, consistent with the important role that miRNAs play in development $[34,45]$. While it has been previously shown that transcription regulators and development genes are commonly targeted by miRNAs $[25,32]$, these results show that some are targeted by a 


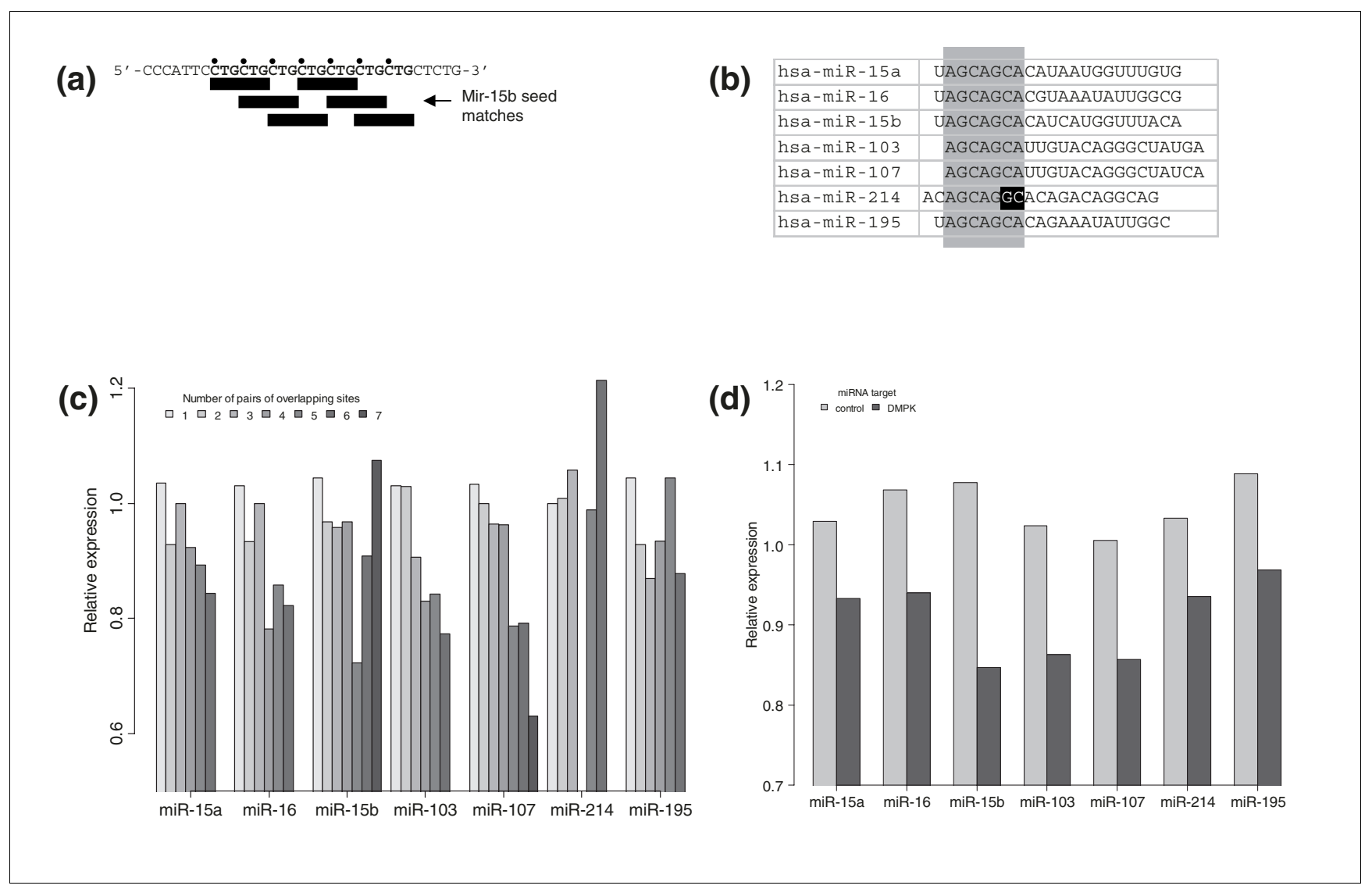

Figure 4

CTG repeat-binding miRNAs and their repression of pairs of extensively overlapping sites. (a) A diagram showing how a region of NM_I73354 containing seven CTG repeats can result in six binding site seeds (CTGCTG) and five pairs of extensively overlapping sites (pairs of binding sites 3 bp apart). (b) Seven miRNAs containing CAG-rich seed regions that are predicted to bind to CTG repeats. Only hsa-miR-2I4 has mismatches in the seed region. (c) Number of overlapping binding sites versus relative expression for seven CTG repeat-binding miRNAs. In general, as the number of pairs of extensively overlapping sites increases, the degree of repression increases. In particular, mirs-107, -103, and -15a show a strong correlation. (d) Decreased relative expression of wild-type DMPK with respect to seven CTG repeat-binding miRNAs suggests repression of mutated DMPK by miRNAs could play a role in DMI. Targets with no overlapping pairs of sites served as control and showed no overall repression.

disproportionate number of miRNAs, suggesting they are under particularly strong miRNA regulation. Interestingly, the enrichment for these GO categories is dependent on the number of distinct miRNAs; no such selection was observed when considering genes targeted by fewer than five miRNAs (Figure $5 \mathrm{~b}, \mathrm{c}$ ). The strong enrichment for various gene categories and the correlation of number of miRNAs targeting a gene and category enrichment supports the notion that highly targeted genes represent a real functional class of genes.

Next, we explored the impact of 3 ' UTR length on the number of miRNAs predicted to target a gene. Since genes targeted by multiple miRNAs necessarily have more miRNA binding sites, it was possible that highly targeted genes result solely from having longer 3' UTRs. Therefore, the enrichment for transcriptional regulators among highly targeted genes, for instance, might result from transcriptional regulators in general having longer 3 ' UTRs. To control for this possibility, we performed a permutation-based experiment to see if random genes having the same average 3' UTR length and gene set size as the test category would be equally enriched for genes targeted by multiple miRNAs (see Materials and methods for details). We found that for both transcriptional regulators and nuclear factors, the enrichment of genes targeted by 10 or more miRNAs is still statistically significant after controlling for 3 ' UTR length (Figure 5d). Thus, highly targeted genes are enriched for transcriptional regulators and nuclear factors independent of 3' UTR length.

We next examined if highly targeted genes might be more tightly regulated, since more miRNAs could potentially repress them at any given time. Given this hypothesis, highly targeted genes might be expected to have, on average, lower expression than less targeted genes. When analyzing expression microarray data from a panel of normal tissues [46], we found that, in a majority of samples, highly targeted genes ( $n$ $>20$ ) in fact exhibited a lower median absolute expression than less targeted genes $\left(1 \leq n \leq 5 ; P=1 \times 10^{-11}\right.$; Figure 6a). 
Table I

The 50 genes targeted by the most miRNAs using PicTar target predictions

\begin{tabular}{|c|c|c|c|}
\hline Gene symbol & No. of miRNAs targeting gene & Refseq ID & Entrez gene description \\
\hline ATXNI & 65 & NM_000332 & Ataxin I \\
\hline CPEB4 & 63 & NM_030627 & $\begin{array}{l}\text { Cytoplasmic polyadenylation } \\
\text { element binding protein } 4\end{array}$ \\
\hline MECP2 & 62 & NM_004992 & $\begin{array}{l}\text { Methyl cpg binding protein } 2 \text { (Rett } \\
\text { syndrome) }\end{array}$ \\
\hline OTUD4 & 61 & NM_199324 & OTU domain containing 4 \\
\hline OGT & 60 & NM_003605 & $\begin{array}{l}\text { O-linked N-acetylglucosamine } \\
\text { (glcnac) transferase (UDP-N- } \\
\text { acetylglucosamine:polypeptide-N- } \\
\text { acetylglucosaminyl transferase) }\end{array}$ \\
\hline PURB & 60 & NM_033224 & $\begin{array}{l}\text { Purine-rich element binding } \\
\text { protein B }\end{array}$ \\
\hline $\mathrm{EIF} 2 \mathrm{Cl}$ & 58 & NM_012199 & $\begin{array}{l}\text { Eukaryotic translation initiation } \\
\text { factor } 2 \mathrm{C}, \mathrm{I}\end{array}$ \\
\hline CPEB2 & 54 & NM_I82485 & $\begin{array}{l}\text { Cytoplasmic polyadenylation } \\
\text { element binding protein } 2\end{array}$ \\
\hline PLAGI & 53 & NM_002655 & Pleiomorphic adenoma gene I \\
\hline NOVAI & 53 & NM_006489 & $\begin{array}{l}\text { Neuro-oncological ventral antigen } \\
\text { I }\end{array}$ \\
\hline DYRKIA & 52 & NM_I0I395 & $\begin{array}{l}\text { Dual-specificity tyrosine-(Y)- } \\
\text { phosphorylation regulated kinase } \\
\text { IA }\end{array}$ \\
\hline HIC2 & 49 & NM_0I5094 & Hypermethylated in cancer 2 \\
\hline RAP2C & 49 & NM_02II83 & $\begin{array}{l}\text { RAP2C, member of RAS oncogene } \\
\text { family }\end{array}$ \\
\hline TRPSI & 48 & NM_0I4II2 & Trichorhinophalangeal syndrome I \\
\hline NARGI & 48 & NM_057I 75 & NMDA receptor regulated I \\
\hline NLK & 47 & NM_0I623I & Nemo like kinase \\
\hline $\mathrm{BACH} 2$ & 47 & NM_021813 & $\begin{array}{l}\text { BTB and CNC homology I, basic } \\
\text { leucine zipper transcription factor } \\
2\end{array}$ \\
\hline KLFI2 & 47 & NM_007249 & Kruppel-like factor 12 \\
\hline QKI & 46 & NM_206853 & $\begin{array}{l}\text { Quaking homolog, } \mathrm{KH} \text { domain } \\
\text { RNA binding (mouse) }\end{array}$ \\
\hline CPEB3 & 46 & NM_0I49I2 & $\begin{array}{l}\text { Cytoplasmic polyadenylation } \\
\text { element binding protein } 3\end{array}$ \\
\hline USP6 & 46 & NM_004505 & $\begin{array}{l}\text { Ubiquitin specific peptidase } 6 \text { (Tre- } \\
2 \text { oncogene) }\end{array}$ \\
\hline YTHDF3 & 45 & NM_I52758 & YTH domain family, member 3 \\
\hline ESRRG & 45 & NM_206594 & Estrogen-related receptor gamma \\
\hline CCND2 & 44 & NM_001759 & Cyclin D2 \\
\hline $\mathrm{CCNJ}$ & 44 & NM_0I9084 & Cyclin J \\
\hline RSBNI & 44 & NM_0I8364 & Round spermatid basic protein I \\
\hline NFAT5 & 44 & NM_I732|4 & $\begin{array}{l}\text { Nuclear factor of activated T-cells } \\
5 \text {, tonicity-responsive }\end{array}$ \\
\hline CAMTAI & 44 & NM_0I52I5 & $\begin{array}{l}\text { Calmodulin binding transcription } \\
\text { activator I }\end{array}$ \\
\hline CNOT6 & 43 & NM_0I5455 & $\begin{array}{l}\text { CCR4-NOT transcription } \\
\text { complex, subunit } 6\end{array}$ \\
\hline E2F3 & 43 & NM_001949 & E2F transcription factor 3 \\
\hline CHESI & 43 & NM_005197 & Checkpoint suppressor I \\
\hline ANK2 & 43 & NM_00II 48 & Ankyrin 2, neuronal \\
\hline MAP3К 3 & 43 & NM_00240I & $\begin{array}{l}\text { Mitogen-activated protein kinase } \\
\text { kinase kinase } 3\end{array}$ \\
\hline
\end{tabular}


Table I (Continued)

The 50 genes targeted by the most miRNAs using PicTar target predictions

\begin{tabular}{|c|c|c|c|}
\hline DNAJCI3 & 42 & NM_015268 & $\begin{array}{l}\text { Dnaj }(\mathrm{Hsp} 40) \text { homolog, subfamily } \\
\mathrm{C} \text {, member } 13\end{array}$ \\
\hline MNT & 42 & NM_020310 & MAX binding protein \\
\hline PPARGCIA & 41 & NM_01326I & $\begin{array}{l}\text { Peroxisome proliferative activated } \\
\text { receptor, gamma, coactivator I, } \\
\text { alpha }\end{array}$ \\
\hline TRIM2 & 41 & NM_01527I & Tripartite motif-containing 2 \\
\hline ZNF238 & 41 & NM_006352 & Zinc finger protein 238 \\
\hline PAFAHIBI & 41 & NM_000430 & $\begin{array}{l}\text { Platelet-activating factor } \\
\text { acetylhydrolase, isoform lb, alpha } \\
\text { subunit } 45 \mathrm{kDa}\end{array}$ \\
\hline HMGA2 & 41 & NM_003483 & High mobility group AT-hook 2 \\
\hline FNDC3B & 41 & NM_022763 & $\begin{array}{l}\text { Fibronectin type III domain } \\
\text { containing } 3 \mathrm{~B}\end{array}$ \\
\hline $\mathrm{FBXO} 33$ & 40 & NM_20330I & F-box protein 33 \\
\hline STCI & 40 & NM_003I55 & Stanniocalcin I \\
\hline CPD & 40 & NM_00I304 & Carboxypeptidase D \\
\hline $\mathrm{CHD} 9$ & 40 & NM_025I34 & $\begin{array}{l}\text { Chromodomain helicase DNA } \\
\text { binding protein } 9\end{array}$ \\
\hline KIAA026I & 40 & NM_0I5045 & Kiaa026I \\
\hline RNF38 & 40 & NM_02278I & Ring finger protein 38 \\
\hline BAZ2A & 39 & NM_013449 & $\begin{array}{l}\text { Bromodomain adjacent to zinc } \\
\text { finger domain, } 2 \mathrm{~A}\end{array}$ \\
\hline CBFA2T3 & 39 & NM_I7593| & $\begin{array}{l}\text { Core-binding factor, runt domain, } \\
\text { alpha subunit } 2 \text {; translocated to, } 3\end{array}$ \\
\hline FNDC3A & 39 & NM_014923 & $\begin{array}{l}\text { Fibronectin type III domain } \\
\text { containing } 3 \mathrm{~A}\end{array}$ \\
\hline
\end{tabular}

More strikingly, in available NCI6o cancer cell line data all 58 samples had lower expression among highly targeted genes $(P$ $=7 \times 10^{-18}$; Figure $\left.6 \mathrm{~b}\right)$. These results support a combinatorial model of miRNA regulation, where different miRNAs simultaneously repress highly targeted genes to yield a lower average expression.

The possibility that many of these genes are tightly guarded by multiple miRNAs suggested that the dysregulation of these genes could lead to undesirable events, such as the development of diseases like cancer. Considering cancer-related genes from the Cancer Gene Census [47], we found that the enrichment for cancer genes was most pronounced in genes targeted by $>30$ miRNAs (over four-fold enrichment, $P=2 \times$ 10-4; Figure 6c). By contrast, housekeeping genes, which are highly conserved, had no enrichment, removing the possibility that conserved genes in general have more miRNAs targeting them (Figure 6c). We tested whether the enrichment for cancer genes was simply due to the overrepresentation of transcription factors, which are known to be common among cancer genes, but the enrichment remained after subtracting out transcription factors (Figure 6d).

To determine whether cancer genes as a class are preferentially targeted by multiple miRNAs, we computed the average number of miRNAs targeting cancer-related genes. On average, 5.6 miRNAs targeted the cancer genes, over 7 standard deviations higher than what would be expected by chance $(P$ $=2 \times 10^{-13}$ ). The same increased multiple targeting of cancer genes was observed when using two other algorithms, TargetScanS and miRanda [24,25] $\left(P=4 \times 10^{-18}\right.$ and $P=4 \times 10^{-8}$, respectively). Likewise, pruning miRNA families with multiple members also did not attenuate the signal (data not shown). Although many of the predicted miRNA targets are not experimentally verified, the overwhelming trends we observed will likely hold despite potential noise in the datasets.

\section{Discussion}

In this study, we examined both single and multiple targeting of miRNAs and their effects on repression. Because of the farranging effects of miRNA repression, it is likely that miRNAs are involved in many diseases as well. In the case of multiple targeting, we show that cancer genes tend to be targeted by more miRNAs, supporting the notion that miRNAs play a role in cancer. In the case of single targeting, we describe below a possible relationship between miRNAs and DM1, using observations about the repression of genes containing 
(a)

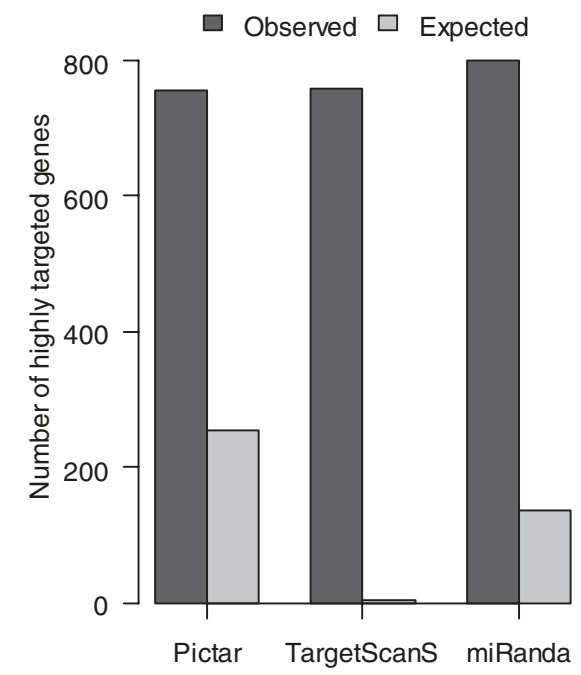

(c)

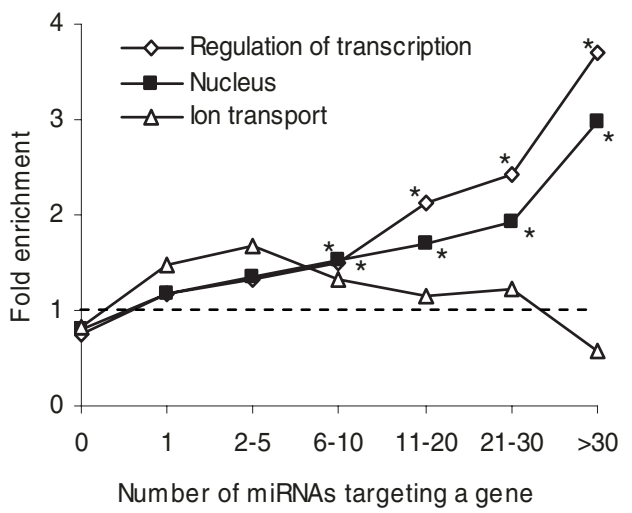

(b)

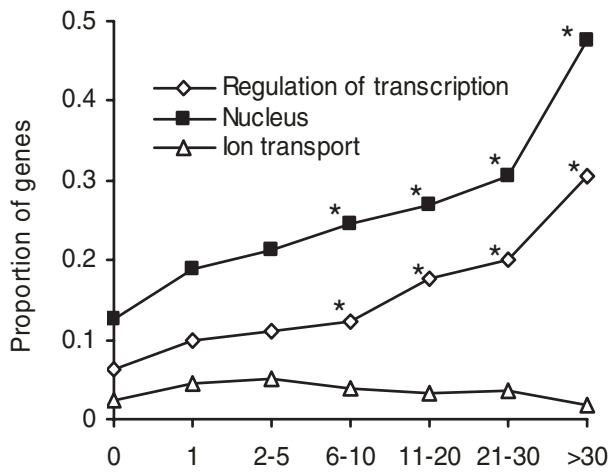

Number of miRNAs targeting a gene

(d)

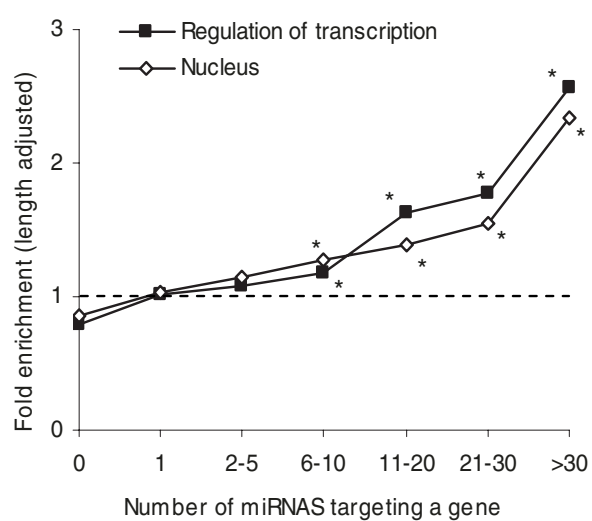

\section{Figure 5}

Abundance and functional enrichment of genes targeted by many distinct miRNAs. (a) The observed number of genes targeted by many miRNAs is dramatically greater than the expected number for all three algorithms. The threshold for the number of miRNAs to be considered highly targeted is defined to be one standard deviation more than the average number of miRNAs predicted to target a gene. (b) A large proportion of genes targeted by many miRNAs are transcriptional regulators and nuclear genes, but this enrichment decreases as the number of miRNAs is reduced. Genes involved in ion transporters do not show this trend. In (b-d), asterisks denote $P<0.01$. (c) Enrichment, instead of proportion (as before), is shown of transcriptional regulators and nuclear genes for highly targeted genes, with the same enrichment for highly targeted genes. The expected enrichment for a random set of genes targeted by any number of miRNAs is I.0 (that is, no enrichment), shown by the dotted line. (d) The enrichment of transcriptional regulators and nuclear genes among highly targeted genes remains after controlling for 3' UTR length.

multiple pairs of overlapping binding sites. These links to diseases underline the importance of studying the mechanisms behind miRNA targeting, which we discuss in the following.

\section{Understanding multiple targeting}

The fundamental motivation for having multiple miRNAs target a gene is so that these presumably important genes can be regulated in a variety of conditions such as different tissue types or transcriptional programs. While it is known that some genes have recognition sites for multiple different miRNAs, it is uncertain whether multiple miRNAs simply supplement each other in different conditions or they act in concert to provide enhanced gene repression. In a simple model, each miRNA would be independently responsible for regulating genes that need to be repressed for a given condition (for example, a specific tissue type). For genes that need to be active under a number of specific conditions, a different miRNA could be expressed under each condition that that gene needed to be regulated. MiRNAs would, therefore, act independently of each other, so that in the case that multiple miRNAs happened to be expressed simultaneously, there would not necessarily be any enhanced repression. 
Table 2

\begin{tabular}{|c|c|c|c|c|}
\hline Category & Term & Count & $\%$ & $P$ value \\
\hline Biological Process 5 & $\begin{array}{l}\text { Regulation of nucleobase, } \\
\text { nucleoside, nucleotide and } \\
\text { nucleic acid metabolism }\end{array}$ & 51 & 30.91 & $5.55 \mathrm{E}-12$ \\
\hline Biological Process 4 & Homophilic cell adhesion & 15 & 9.09 & I.82E-I I \\
\hline Biological Process 5 & Transcription & 51 & 30.91 & $1.96 \mathrm{E}-\mathrm{II}$ \\
\hline Biological Process 4 & $\begin{array}{l}\text { Regulation of cellular } \\
\text { metabolism }\end{array}$ & 54 & 32.73 & $9.26 \mathrm{E}-\mathrm{II}$ \\
\hline Biological Process 3 & $\begin{array}{l}\text { Nervous system } \\
\text { development }\end{array}$ & 23 & 13.94 & $1.49 \mathrm{E}-10$ \\
\hline Biological Process 3 & Regulation of metabolism & 54 & 32.73 & I.7IE-10 \\
\hline Biological Process 3 & $\begin{array}{l}\text { Regulation of cellular } \\
\text { physiological process }\end{array}$ & 61 & 36.97 & $2.46 \mathrm{E}-09$ \\
\hline Biological Process 3 & Cell-cell adhesion & 15 & 9.09 & I. $10 \mathrm{E}-08$ \\
\hline Biological Process 4 & $\begin{array}{l}\text { Nucleobase, nucleoside, } \\
\text { nucleotide and nucleic acid } \\
\text { metabolism }\end{array}$ & 56 & 33.94 & $5.15 \mathrm{E}-06$ \\
\hline Cellular Component 3 & Nucleus & 72 & 43.64 & I.3IE-08 \\
\hline Cellular Component 3 & $\begin{array}{l}\text { Intracellular membrane- } \\
\text { bound organelle }\end{array}$ & 79 & 47.88 & 2.9IE-04 \\
\hline Molecular Function 3 & DNA binding & 49 & 29.70 & I. $12 \mathrm{E}-08$ \\
\hline Molecular Function 4 & $\begin{array}{l}\text { Transcription factor } \\
\text { activity }\end{array}$ & 30 & 18.18 & $8.45 \mathrm{E}-08$ \\
\hline Molecular Function 3 & Metal ion binding & 64 & 38.79 & I.87E-07 \\
\hline Molecular Function 3 & Cation binding & 60 & 36.36 & $6.06 \mathrm{E}-07$ \\
\hline Molecular Function 5 & Zinc ion binding & 35 & 21.21 & 6.33E-05 \\
\hline Molecular Function 4 & Calcium ion binding & 23 & 13.94 & $6.74 \mathrm{E}-05$ \\
\hline Molecular Function 4 & $\begin{array}{l}\text { Sequence-specific DNA } \\
\text { binding }\end{array}$ & 14 & 8.48 & 4.49E-04 \\
\hline Molecular Function 5 & $\begin{array}{l}\text { Transcription corepressor } \\
\text { activity }\end{array}$ & 6 & 3.64 & I. $12 \mathrm{E}-03$ \\
\hline Molecular Function 3 & $\begin{array}{l}\text { Transcription corepressor } \\
\text { activity }\end{array}$ & 6 & 3.64 & I.69E-03 \\
\hline Molecular Function 5 & $\begin{array}{l}\text { Calcium-transporting } \\
\text { atpase activity }\end{array}$ & 3 & 1.82 & $6.05 \mathrm{E}-03$ \\
\hline
\end{tabular}

Significant terms $(P<0.01)$ from levels $3-5$ of each ontology are shown.

A more intriguing model involves multiple miRNAs working in concert to repress a gene. In this case, two different miRNAs expressed independently could each repress a given gene. If both miRNAs are expressed simultaneously, however, then that gene is much more strongly repressed than the repression exerted by each miRNA on its own. This coordinated regulation is achieved in transcriptional regulation when two transcriptional factors interact in a transcriptional complex while binding to the promoter of a gene. Since miRNAs are much smaller than transcription factors and, therefore, have little of a binding interface, it is unlikely that miRNAs could directly interact. It is possible that miRNA complexes (as part of a RISC complex) could instead interact, but the binding interfaces to these complexes would need to exhibit some unique characteristic of that miRNA to differentiate one complex from another. Another possibility is that two binding sites responsive to different miRNAs may have different repressive potential depending on the distances between the two sites, similar to the results shown above for a single miRNA on multiple sites. Independent of the mechanism, the fine degree of regulation allowed by coordinate miRNA repression makes this an appealing model that deserves further attention. Our observation that genes targeted by more miRNAs tend to be repressed more than genes targeted by fewer miRNAs is consistent with the combinatorial model where both the degree and specificity of miRNA regulation can be modulated by various combinations of relevant miRNAs. 
(a)

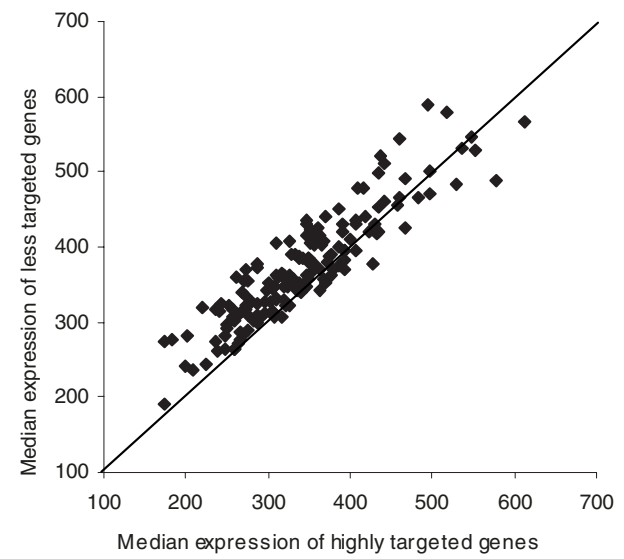

(c)

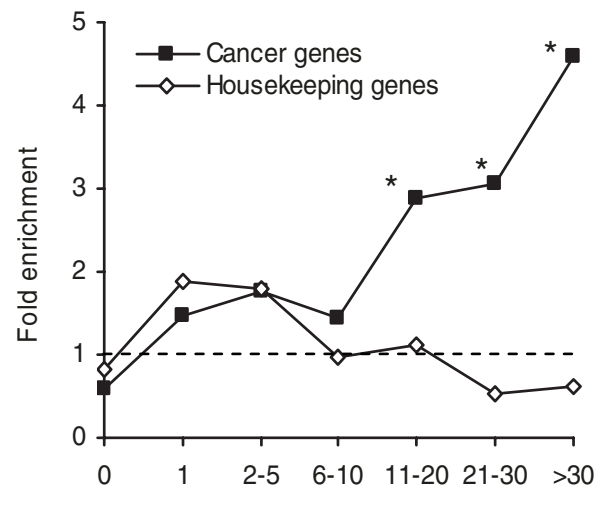

Number of miRNAs targeting a gene (b)

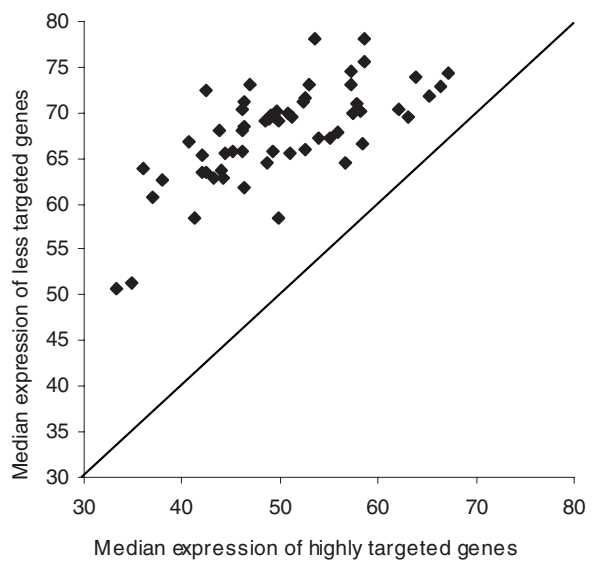

(d)

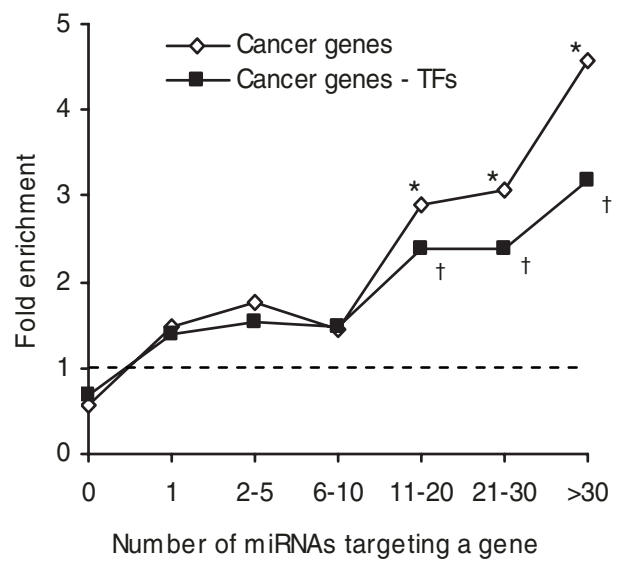

Figure 6

Downregulated expression and enrichment of cancer genes among highly targeted genes. (a) In a comparison of highly targeted genes ( $\mathrm{n}>20$ ) versus less targeted genes $(I \leq n \leq 5)$ in normal tissue samples [46], I2I out of I58 samples exhibited decreased expression among highly targeted genes $(P=I \times I 0$ II). (b) Out of $58 \mathrm{NCl} 60$ cancer cell line samples, 58 exhibited decreased expression among highly targeted genes $\left(P=7 \times 10^{-18}\right)$. (c) Highly targeted genes are enriched for cancer genes, with cancer genes targeted by $>30$ miRNAs having the most enrichment. In (c,d), asterisks denote $P<0.01$ and crosses denote $P<0.05$.(d) This enrichment for cancer genes remains after removing transcriptional regulators, which are prevalent among cancer genes and, as shown earlier, overrepresented among highly targeted genes.

\section{CTG repeat-binding miRNAs and link to myotonic dystrophy}

Our observation that CTG repeat length correlates with miRNA repression led us to surmise a possible role for this phenomenon in disease, in particular DM1. If a 3' UTR were to gain CTG repeats, it would be possible to abnormally repress that transcript, affect the stoichiometry of free to bound CTG-repeat binding miRNAs, or otherwise disrupt CTG-repeat binding miRNA function. We focused on DM1 because CTG repeat expansion in DMPK has been shown to be the cause of the disease and because the detailed mechanism for DM1 pathogenesis remains unresolved.
We therefore propose that miRNA repression of CTG repeats plays a role in the mechanism of DM1. In this model, CTG repeat-binding miRNAs, such as mir-107 and mir-103, preferentially bind to the mutated $D M P K$ transcript. This could have two miRNA-leaching effects: first, the amount of unbound miRNA that would normally be regulating other genes is reduced and could no longer repress other target genes; or second, the strength of the repression due to long CTG repeats could result in the sequestration of large amounts of miRNA machinery and prevent normal miRNA repression in general. MiRNA involvement could have significant consequences on known proteins in DM1 disease pro- 
gression. In the current view, the CTG repeat expansion triggers sequestration of the $D M P K$ transcript into nuclear foci [48] along with $M B N L$ [49], implicating $M B N L$ as a key player in DM pathogenesis. Instead of the prevalent view that $M B N L$ binds directly to DMPK mRNA, $M B N L$ might instead be responsive to the complex with miRNAs binding to the DMPK 3' UTR.

This proposed relationship between $M B N L$ and miRNAs might explain why colocalization of $M B N L$ with RNA foci does not necessarily trigger DM1 downstream events [50] and why MBNL1 apparently binds to other types of repeats even better than CTG repeats [51]; in both cases, miRNA-binding to CTG repeats might mediate this interaction. One potential complication to this theory is that while, traditionally, miRNA biogenesis assumes that mature miRNA is active only within the cytoplasm, miRNA binding to DMPK transcripts would require that miRNAs and their machinery exist within the nucleus. In fact, recent evidence has shown that miRNAs are also active within the nucleus [52], facilitated by a nuclear import mechanism [53].

Several lines of evidence support our theory that miRNAs might be involved in DM1. First, as we showed earlier, miRNA repression increased as the length of CTG repeats increased, suggesting a relationship between CTG repeat length and miRNA repression. Second, we also showed that wild-type $D M P K$ is responsive to repression by CTG repeat-binding miRNAs. Additionally, disrupting miRNA biogenesis through the knockdown of Dicer has been shown to increase DMPK expression [54], suggesting that miRNAs regulate DMPK. Finally, the model implies that CTG repeat-binding miRNAs should be expressed in the tissues that exhibit DM1 symptoms. Using published mouse miRNA expression data [55], we found that our strongest candidates, mir-107 and mir-103, are indeed strongly expressed in brain, heart, and muscle. Together, these results support a role for miRNAs in DM1 pathogenesis, and, in particular, highlight mir-107 and mir103 as attractive candidates for binding to $D M P K$.

\section{Observations about the relative expression metric}

The RE metric as used in this paper is unique compared to previous efforts in understanding miRNA targeting in that both miRNA and mRNA expression data have been used together to measure miRNA repression. Previous efforts utilizing only expression microarray or in situ hybridization data indirectly measured differential expression of mRNA targets by taking advantage of knowledge about tissue- or stage-specific expression of miRNAs. For example, since mir-1 tends to be expressed in skeletal muscle, it is expected that targets of mir-1 should be downregulated in muscle samples. However, miRNA expression characteristics can be inferred for only a limited number of miRNAs for a given sample type. In this approach, the experimentally derived expression of many different miRNAs is known for multiple samples, making it possible to calculate the differential expression of target genes using measurements of actual miRNA expression levels. Using this approach, we performed an in silico genome-wide assessment of binding site-specific characteristics of miRNA repression, including the number of binding sites, distances between binding sites, pairs of extensively overlapping sites, and length of the 3' UTR. While some of these morphological features have been previously discussed as factors linked to or contributing to miRNA repression, they had generally been studied under specific and limited experimental conditions or in the context of miRNA target predictions without regard to expression data.

Because the Lu et al. dataset [21] used here comprises a heterogeneous set of samples drawn from different tissue types and cancer status, tissue- and cancer-specific gene expression complicates analysis of miRNA repression. For this reason, housekeeping genes, which are universally expressed, served to reduce variation in gene expression across different tissues due to non-miRNA specific effects. It is also for this reason that we chose to employ the RE metric and not a correlation metric. Because of the complexity of the data, the expected anti-correlations that correspond to repression tend to be very slight and, therefore, difficult to interpret. Additionally, the RE metric corresponds more closely to the concept of degree of repression, where smaller RE values correspond to down-regulation and thus greater repression.

While larger changes have been observed in translational inhibition by miRNAs compared with transcriptional repression, the relatively small changes in RE values that we observed nevertheless emphasize the importance of miRNAmediated transcriptional repression. As we showed, the 5$10 \%$ lower RE values for a set of gene interactions is in line with the average repression of target genes in cells transfected with miRNA in Lim et al. [15]. Importantly, both calculations are based on a large number of gene targets, and, therefore, subject to various sources of noise and uncertainty. These include the possibility that some genes might be more strongly repressed by a miRNA than others, that some gene targets might have been mis-predicted by PicTar, or that some gene targets might only be expressed or responsive to a miRNA in certain tissues. Despite these potential sources of noise, our ability to detect the observed trends shows that the results are applicable genome-wide and emphasize the role of miRNA repression at the transcriptional level. Since it appears that the same sequence features (that is, the distance between binding sites) can influence repression both at the translational level [29] and transcriptional level (shown here), this suggests that the mechanisms driving miRNAmediated transcriptional and translational repression may be linked.

One unexpected observation was the presence of RE values greater than 1.0 in various analyses. This effect is possible if considered within the context of total gene regulation, where multiple factors compete to up- and downregulate a gene. In 
this scenario, transcription factors and miRNAs that are simultaneously expressed exert opposing effects on the regulation of genes. If, on balance, a gene experiences greater transcriptional activation than miRNA repression, then this gene could exhibit RE values greater than 1.0 despite the miRNA repression. This apparent upregulation in the presence of miRNA repression should not be considered surprising given the belief that miRNAs serve to fine-tune gene regulation in feedback loops, increasing the precision and robustness of gene expression $[31,56,57]$.

We anticipate that the RE metric will be able to reveal additional features of miRNA repression when applied to larger datasets containing more uniform data, such as those containing the same tissues or cancer state. Some potential experiments include testing for cooperative effects of multiple miRNAs working together to repress a gene, interactions between miRNAs and transcription factors when targeting a gene, and binding site specific effects, such as the importance of the seed region or the tolerability of $\mathrm{G} / \mathrm{U}$ mismatches.

\section{Conclusion}

Through the integration of miRNA target predictions and miRNA and mRNA expression data, we have been able to analyze features of single and multiple targeting. We first showed that a relative expression metric could be used to measure the degree of repression by miRNAs, demonstrating that 3' UTR length, number of binding sites responsive to a miRNA, and distance between two binding sites responsive to the same miRNA are all important factors that influence miRNA repression. Interestingly, we also showed that miRNA repression increases as the number of pairs of extensively overlapping sites increases, in many cases due to regions of CTG repeats. This creates the possibility that miRNA repression of CTG repeats might be involved in diseases that involve expansions in CTG repeats, such as DM1, for which we had some preliminary evidence. We then analyzed genes that are targeted by multiple miRNAs and found an unexpected abundance of such genes, with significant enrichment for transcriptional regulators and nuclear genes. Exploring the notion that highly targeted genes might be more tightly regulated, we demonstrated that highly targeted genes are downregulated relative to less targeted genes. Finally, supporting the idea that dysregulation of tightly regulated genes could lead to disease, we showed that highly targeted genes were enriched for cancer genes. The results presented here show that approaches that integrate multiple types of data are a powerful way to elucidate miRNA mechanisms in both single and multiple targeting and can further our understanding of disease.

\section{Materials and methods \\ Datasets}

We utilized expression data from 89 samples from Lu et al. [21] and Ramaswamy et al. [40], for which both miRNA and mRNA expression data are available. Both datasets underwent data preprocessing as described by Lu et al. This resulted in 195 miRNAs and 14,546 mRNAs available to be used for analysis. We also obtained expression data from the NCI-6o set of cell lines, using miRNA expression data from Blower et al. [58] and mRNA data from Genelogic [59]. For the NCI-6o miRNA data, we followed the data normalization as described by Blower et al. and for each miRNA used the probe that had the higher median expression. For the NCI-60 mRNA data, we set a minimum log2 expression value of 5 . For the multiple targeting analysis, we used, in addition, the NCI60 cancer cell line gene expression dataset, generated by Novartis based on the Affymetrix U95v2 array platform, and the normal human tissue expression dataset based on the Affymetrix U133A array platform [46].

For the multiple targeting analysis, we used miRNA target prediction data obtained from PicTar [23], TargetScanS [24], and miRanda [25]. For PicTar, we chose the results based on conservation in human, chimp, mouse, rat, and dog. For TargetScanS predictions we chose the four species comparison and only SeedM matching to increase the number of predictions available. In the single targeting analysis, to increase the number of binding site predictions available, we used the updated PicTar algorithm [6o], which includes sites that may not be fully conserved. We also used publicly available rna22 target predictions $[27,61]$, which predicts relatively fewer sites per target gene and, therefore, was used for analyses that depend less on having multiple sites per target gene.

For the locations of predicted miRNA binding sites within the 3' UTR, we mapped the sequences onto Release 16 of RefSeq [62] transcripts. 3 ' UTR lengths of genes were also extracted from the RefSeq data. We obtained 340 cancer-related genes from the Cancer Gene Census [47], and 556 genes designated as housekeeping genes from Eisenberg and Levanon [42].

\section{Relative expression metric}

The RE metric as applied to miRNA and mRNA expression data is an estimate of the degree of repression of a gene (at the transcriptional level) resulting from a miRNA binding to a target transcript. To calculate the RE for a given gene repressed by a given miRNA, for $n$ samples for which both miRNA and mRNA expression data are available, we first sort the samples by miRNA expression. We then equally divide the samples into two groups, group A with low miRNA expression (samples 1 to $n / 2$ ), and group B with high miRNA expression (samples $n / 2+1$ to $n$ ). The RE is thus the ratio of the median mRNA expression of samples in group B divided by the median mRNA expression of samples in group A. Interactions with strong miRNA repression yield smaller RE values, since group B should have lower mRNA expression because of the 
higher miRNA expression, and group A should have higher mRNA expression because of the lower mRNA expression. The experiments are illustrated in Additional data file 1.

To focus on miRNA-mRNA interactions with the most potential signal, we considered the subset of interactions with sufficient variation among the samples. For analysis of 3' UTR lengths, we considered only miRNAs where, for each miRNA, the median miRNA expression in group B (samples with high miRNA expression) was at least four times greater than the median miRNA expression in group A (samples with low miRNA expression). In the experiment considering the number of binding sites versus repression, we only required that the two groups have different median miRNA expression to maximize the number of interactions available. Additionally, for all experiments, we removed interactions for which there was no difference in median mRNA expression between the two groups. The average relative expression for a particular condition was defined to be the median of the remaining $\mathrm{RE}$ values that satisfy that condition. The significance of a group of RE values was assessed using the double-sided $t$ test; for the tests shown, varying the thresholds did not significantly affect the $P$ value.

To determine the expected RE values for a given experiment, we created a null distribution of experiments, where for a given miRNA randomized miRNA expression values were used so that the samples used in groups A and B would be scrambled. The expected value consists of ten permutations of this data, from which the error bar is derived.

\section{Maximum expected repression}

To determine if a $10 \%$ repression was reasonable using the RE metric, we examined the downregulation of miRNA target genes using data from Lim et al. [15]. To choose a subset of miRNA predicted targets with the largest possible repression, we sorted the gene targets by the degree of downregulation and identified the top $10 \%$ most downregulated targets. A separate set of predicted targets was defined using 3' UTRs that contain 7-mer seed matches to the miRNA (positions 28).

\section{Distance between binding sites}

We defined a pair of binding sites to be two binding sites responsive to the same miRNA, for which there are no other binding sites responsive to that miRNA in between them. The distance between the pair of binding sites was calculated based on the 5 ' end of the binding site relative to the mRNA transcript. To identify distance ranges having significantly increased repression, we used a 10 bp sliding window of distances for distances between 1 and 100 bp apart, and performed a double-sided $t$-test between RE values contained in the window versus $\mathrm{RE}$ values outside of the window, using a Bonferroni correction of 90 hypotheses.

\section{Number of miRNAs that target a gene}

For each transcript, we tallied the number of different miRNAs predicted to target that transcript. For genes with multiple transcripts, a representative transcript was chosen, so that results could be reported at the gene level.

\section{Enrichment analysis}

We used DAVID [63] to determine enrichment of types of genes within the highly miRNA-targeted genes, focusing on gene sets obtained from GO [64]. Significance was assessed using the EASE score from DAVID [63], a modified Fisher's Exact Test. Fisher's Exact Test was used to determine the significance of the enrichment of a subset of genes targeted by a range of miRNAs shown in the figures. Enrichment was calculated in the following way: if, for a gene set $R$, among all genes genome wide $G$, we observe $R_{s}$ (a subset of $R$ ) within $G_{s}$ (a subset of $G$ ), then the enrichment of $R$ within this subset is $\frac{R_{S} / G_{S}}{R / G}$, where the observed proportion of $R_{s}$ is $R_{s} / G_{s}$ and the expected proportion of $R_{s}$ is $R / G$. A multiple testing significance threshold can be conservatively defined in this enrichment analysis by applying a Bonferroni correction to yield $P<$ $5 \times 10^{-5}$ as the adjusted $P$ value required for significance (given approximately 1,00o GO categories used by DAVID).

\section{Statistical tests}

The statistical significance of seeing a number of genes targeted by at least a lower threshold $n$ miRNAs was computed using permutation testing. For a given algorithm's target predictions, we determined the number of targets a given miRNA targeted, and assigned the same number of random genes to that miRNA. In the case that a miRNA belonged to a family of miRNAs, we assigned the same set of random genes to all of the miRNAs in that family. This procedure was repeated 1,00o times, and the $P$-value could be assessed by determining the fraction of permutations that the number of genes targeted by at least $n$ miRNAs was greater than the observed number of genes. To account for differences in the algorithms, for each algorithm we defined $n$ to be one standard deviation more than the average number of miRNAs predicted to target a gene.

Permutation testing was also used to control for the possibility that the enrichment for transcription and nuclear factors targeted by multiple miRNAs was due to longer 3' UTRs. To do this, we created a null distribution containing 10,000 random sets of genes with the same average 3' UTR lengths and gene set sizes as those of transcription factors or nuclear proteins, respectively. From this distribution, we determined, for example, the likelihood of seeing 36 transcription factors targeted by > 30 miRNAs, controlled for both 3 ' UTR length and gene set size, based on the number of times more than 36 genes were found to be targeted by $>30$ miRNAs. 
To determine the significance of the number of miRNAs targeting a particular gene set, we examined the mean number of miRNAs targeting the genes in the gene set (referred to hereafter as 'score') and compared it against the null distribution. The null distribution was generated by creating 1,000 random gene sets containing the same number of genes as the test set, and calculating the score for these random gene sets. Because the null distribution is normally distributed, we could compute the $P$ value based on the $\mathrm{z}$-value, where $\mathrm{Z}=$ (observed score - expected score)/standard deviation.

\section{Testing for miRNA family effects}

MiRNAs are known to cluster into families having highly similar binding sites. To avoid having an a priori definition of which miRNAs belong to a family, we instead considered the miRNAs in the context of each target gene. For a given target gene, we tracked the predicted locations of target sites for each miRNA, and we discarded the miRNAs that were predicted to bind to the same location recognized by another miRNA. This would yield a set of miRNAs with unique target sites, predicted to target a gene. This number by definition is less than or equal to the total number of miRNAs that are predicted to target a gene.

\section{Additional data files}

The following additional data are available with the online version of this paper. Additional data file 1 illustrates the different analyses performed using the relative expression metric. Additional data file 2 contains figures using alternative data sets that support the observed trends. Additional data file 3 contains a description of the tables of the raw relative expression data and associated data found in Additional data files $4,5,6,7,8$. Additional data file 4 contains relative expression values for all PicTar predicted interactions using the Lu/Ramaswamy set of expression data. Additional data file 5 contains relative expression values for all PicTar predicted interactions using the NCI-6o set of expression data. Additional data file 6 contains relative expression values for all rna22 predicted interactions using the Lu/Ramaswamy set of expression data. Additional data file 7 contains relative expression values for specific pairs of binding sites (<1000 bp apart) responsive to a miRNA, using Lu/Ramaswamy data and PicTar predictions. Additional data file 8 contains relative expression values for specific pairs of binding sites (<100o bp apart) responsive to a miRNA, using NCI-6o data and PicTar predictions.

\section{Abbreviations}

DM1 = myotonic dystrophy type $1 ;$ GO = Gene Ontology; miRNA $=$ microRNA; $\mathrm{RE}=$ relative expression $;$ RISC $=\mathrm{RNA}-$ induced silencing complex; UTR = untranslated region.

\section{Acknowledgements}

We would like to thank Josh Kaminker, Pete Haverty, Shiuh-Ming Luoh and Yan Zhang for helpful discussions, Guy Cavet, David Dornan, John Chant, Colin Watanabe, and Alex Adai for critical reading of the manuscript, and William Wood for interest and support throughout the project.

\section{References}

I. Griffiths-Jones S, Grocock RJ, van Dongen S, Bateman A, Enright AJ: miRBase: microRNA sequences, targets and gene nomenclature. Nucleic Acids Res 2006, 34:D I 40-I 44.

2. Berezikov E, Guryev V, van de Belt J, Wienholds E, Plasterk RH, Cuppen E: Phylogenetic shadowing and computational identification of human microRNA genes. Cell 2005, I 20:2I-24.

3. Kim VN, Nam JW: Genomics of microRNA. Trends Genet 2006 22:165-173

4. Chen X: MicroRNA biogenesis and function in plants. FEBS Lett 2005, 579:5923-593I.

5. He L, Thomson JM, Hemann MT, Hernando-Monge E, Mu D, Goodson S, Powers S, Cordon-Cardo C, Lowe SW, Hannon G], et al.: A microRNA polycistron as a potential human oncogene. Nature 2005, 435:828-833.

6. Lee Y, Ahn C, Han J, Choi H, Kim J, Yim J, Lee J, Provost P, Radmark $\mathrm{O}, \mathrm{Kim} \mathrm{S}$, et al.: The nuclear RNase III Drosha initiates microRNA processing. Nature 2003, 425:415-4I9.

7. Lund E, Guttinger S, Calado A, Dahlberg JE, Kutay U: Nuclear export of microRNA precursors. Science 2004, 303:95-98.

8. $Y_{i} R$, Qin $Y$, Macara IG, Cullen BR: Exportin-5 mediates the nuclear export of pre-microRNAs and short hairpin RNAs. Genes Dev 2003, 17:30II-3016.

9. Bernstein E, Caudy AA, Hammond SM, Hannon G]: Role for a bidentate ribonuclease in the initiation step of RNA interference. Nature 200I, 409:363-366.

10. Hammond SM, Boettcher S, Caudy AA, Kobayashi R, Hannon G] Argonaute2, a link between genetic and biochemical analyses of RNAi. Science 200I, 293: I I 46- I I 50.

II. Jackson RJ, Standart N: How do microRNAs regulate gene expression? Sci STKE 2007, 2007:rel.

12. Behm-Ansmant I, Rehwinkel J, Doerks T, Stark A, Bork P, lzaurralde E: mRNA degradation by miRNAs and GW 182 requires both CCR4:NOT deadenylase and DCPI:DCP2 decapping complexes. Genes Dev 2006, 20:1885-1898.

13. Schmitter D, Filkowski J, Sewer A, Pillai RS, Oakeley EJ, Zavolan M, Svoboda P, Filipowicz W: Effects of Dicer and Argonaute downregulation on mRNA levels in human HEK293 cells. Nucleic Acids Res 2006, 34:480I-48I5.

14. Wu L, Fan J, Belasco JG: MicroRNAs direct rapid deadenylation of mRNA. Proc Natl Acad Sci USA 2006, 103:4034-4039.

15. Lim LP, Lau NC, Garrett-Engele P, Grimson A, Schelter JM, Castle J, Bartel DP, Linsley PS, Johnson JM: Microarray analysis shows that some microRNAs downregulate large numbers of target mRNAs. Nature 2005, 433:769-773.

16. Krutzfeldt J, Rajewsky N, Braich R, Rajeev KG, Tuschl T, Manoharan $M$, Stoffel M: Silencing of microRNAs in vivo with 'antagomirs'. Nature 2005, 438:685-689.

17. Clop A, Marcq F, Takeda H, Pirottin D, Tordoir X, Bibe B, Bouix J, Caiment F, Elsen JM, Eychenne F, et al: A mutation creating a potential illegitimate microRNA target site in the myostatin gene affects muscularity in sheep. Nat Genet 2006, 38:8I3-8I8.

18. Zhang L, Huang J, Yang N, Greshock J, Megraw MS, Giannakakis A, Liang S, Naylor TL, Barchetti A, Ward MR, et al:: microRNAs exhibit high frequency genomic alterations in human cancer. Proc Natl Acad Sci USA 2006, 103:9136-9141.

19. Esquela-Kerscher A, Slack F): Oncomirs - microRNAs with a role in cancer. Nat Rev Cancer 2006, 6:259-269.

20. Negrini M, Ferracin M, Sabbioni S, Croce CM: MicroRNAs in human cancer: from research to therapy. I Cell Sci 2007, I 20:1833-1840.

21. Lu J, Getz G, Miska EA, Alvarez-Saavedra E, Lamb J, Peck D, SweetCordero A, Ebert BL, Mak RH, Ferrando AA, et al:: MicroRNA expression profiles classify human cancers. Nature 2005, 435:834-838

22. Brennecke J, Stark A, Russell RB, Cohen SM: Principles of microRNA-target recognition. PLOS Biol 2005, 3:e85.

23. Krek A, Grun D, Poy MN, Wolf R, Rosenberg L, Epstein El, MacMenamin P, da Piedade I, Gunsalus KC, Stoffel M, et al.: Combinatorial 
microRNA target predictions. Nat Genet 2005, 37:495-500.

24. Lewis $B P$, Burge $C B$, Bartel DP: Conserved seed pairing, often flanked by adenosines, indicates that thousands of human genes are microRNA targets. Cell 2005, | 20: 15-20.

25. John B, Enright AJ, Aravin A, Tuschl T, Sander C, Marks DS: Human MicroRNA targets. PLoS Biol 2004, 2:e363.

26. Didiano $D$, Hobert $O$ : Perfect seed pairing is not a generally reliable predictor for miRNA-target interactions. Nat Struct Mol Biol 2006, I3:849-85।.

27. Miranda KC, Huynh T, Tay Y, Ang YS, Tam WL, Thomson AM, Lim $B$, Rigoutsos I: A pattern-based method for the identification of MicroRNA binding sites and their corresponding heteroduplexes. Cell 2006, I 26:1203-1217.

28. Vella MC, Choi EY, Lin SY, Reinert K, Slack FJ: The C. elegans microRNA let-7 binds to imperfect let-7 complementary sites from the lin-4 I 3'UTR. Genes Dev 2004, I 8: I32-137.

29. Doench JG, Sharp PA: Specificity of microRNA target selection in translational repression. Genes Dev 2004, 18:504-5 I I.

30. Saetrom P, Heale BS, Snove O Jr, Aagaard L, Alluin J, Rossi JJ: Distance constraints between microRNA target sites dictate efficacy and cooperativity. Nucleic Acids Res 2007, 35:2333-2342.

31. Stark A, Brennecke J, Bushati N, Russell RB, Cohen SM: Animal MicroRNAs confer robustness to gene expression and have a significant impact on 3'UTR evolution. Cell 2005, I 23: I I33-I| 46 .

32. Enright AJ, John B, Gaul U, Tuschl T, Sander C, Marks DS: MicroRNA targets in Drosophila. Genome Biol 2003, 5:RI.

33. Chan CS, Elemento $O$, Tavazoie $S$ : Revealing posttranscriptional regulatory elements through network-level conservation. PLoS Comput Biol 2005, I:e69.

34. Farh KK, Grimson A, Jan C, Lewis BP, Johnston WK, Lim LP, Burge $C B$, Bartel DP: The widespread impact of mammalian MicroRNAs on mRNA repression and evolution. Science 2005, 310:1817-182|.

35. Sood P, Krek A, Zavolan M, Macino G, Rajewsky N: Cell-type-specific signatures of microRNAs on target mRNA expression. Proc Natl Acad Sci USA 2006, I03:2746-275।.

36. Yu Z, Jian Z, Shen SH, Purisima E, Wang E: Global analysis of microRNA target gene expression reveals that miRNA targets are lower expressed in mature mouse and Drosophila tissues than in the embryos. Nucleic Acids Res 2006, 35: 152-164.

37. Ranum LP, Cooper TA: RNA-mediated neuromuscular disorders. Annu Rev Neurosci 2006, 29:259-277.

38. Cho DH, Tapscott SJ: Myotonic dystrophy: Emerging mechanisms for DMI and DM2. Biochim Biophys Acta 2006, I772:195-204.

39. Gatchel JR, Zoghbi HY: Diseases of unstable repeat expansion: mechanisms and common principles. Nat Rev Genet 2005, 6:743-755.

40. Ramaswamy S, Tamayo P, Rifkin R, Mukherjee S, Yeang $\mathrm{CH}$, Angelo M, Ladd C, Reich M, Latulippe E, Mesirov JP, et al:: Multiclass cancer diagnosis using tumor gene expression signatures. Proc Natl Acad Sci USA 200I, 98:15149-15154.

4I. Chiaromonte F, Miller W, Bouhassira EE: Gene length and proximity to neighbors affect genome-wide expression levels. Genome Res 2003, 13:2602-2608.

42. Eisenberg E, Levanon EY: Human housekeeping genes are compact. Trends Genet 2003, 19:362-365.

43. Doench JG, Petersen CP, Sharp PA: siRNAs can function as miRNAs. Genes Dev 2003, 17:438-442.

44. Pillai RS, Artus CG, Filipowicz W: Tethering of human Ago proteins to mRNA mimics the miRNA-mediated repression of protein synthesis. Rna 2004, 10:1518-1525.

45. Wienholds E, Plasterk RH: MicroRNA function in animal development. FEBS Lett 2005, 579:591 I-5922.

46. Su Al, Wiltshire T, Batalov S, Lapp H, Ching KA, Block D, Zhang J, Soden R, Hayakawa M, Kreiman G, et al: A gene atlas of the mouse and human protein-encoding transcriptomes. Proc Natl Acad Sci USA 2004, 10 I:6062-6067.

47. Futreal PA, Coin L, Marshall M, Down T, Hubbard T, Wooster R, Rahman N, Stratton MR: A census of human cancer genes. Nat Rev Cancer 2004, 4: I77-I83.

48. Taneja KL, McCurrach M, Schalling M, Housman D, Singer RH: Foci of trinucleotide repeat transcripts in nuclei of myotonic dystrophy cells and tissues. I Cell Biol I 995, I 28:995-I002.

49. Mankodi A, Urbinati CR, Yuan QP, Moxley RT, Sansone V, Krym M, Henderson D, Schalling M, Swanson MS, Thornton CA: Muscleblind localizes to nuclear foci of aberrant RNA in myotonic dystro- phy types I and 2. Hum Mol Genet 200I, 10:2165-2I70.

50. Ho TH, Savkur RS, Poulos MG, Mancini MA, Swanson MS, Cooper TA: Colocalization of muscleblind with RNA foci is separable from mis-regulation of alternative splicing in myotonic dystrophy. J Cell Sci 2005, I I 8:2923-2933.

5I. Kino Y, Mori D, Oma Y, Takeshita Y, Sasagawa N, Ishiura S: Muscleblind protein, MBNLI/EXP, binds specifically to CHHG repeats. Hum Mol Genet 2004, I 3:495-507.

52. Robb GB, Brown KM, Khurana J, Rana TM: Specific and potent RNAi in the nucleus of human cells. Nat Struct Mol Biol 2005, I 2:133-137.

53. Hwang HW, Wentzel EA, Mendell JT: A hexanucleotide element directs microRNA nuclear import. Science 2007, 3 I 5:97-100.

54. Krol J, Fiszer A, Mykowska A, Sobczak K, de Mezer M, Krzyzosiak WJ: Ribonuclease dicer cleaves triplet repeat hairpins into shorter repeats that silence specific targets. Mol Cell 2007, 25:575-586.

55. Babak T, Zhang W, Morris Q, Blencowe BJ, Hughes TR: Probing microRNAs with microarrays: tissue specificity and functional inference. Rna 2004, 10:18|3-18|9.

56. Cohen SM, Brennecke J, Stark A: Denoising feedback loops by thresholding - a new role for microRNAs. Genes Dev 2006 20:2769-2772.

57. Hornstein E, Shomron N: Canalization of development by microRNAs. Nat Genet 2006, 38(Suppl):S20-24

58. Blower PE, Verducci JS, Lin S, Zhou J, Chung JH, Dai Z, Liu CG, Reinhold W, Lorenzi PL, Kaldjian EP, et al.: MicroRNA expression profiles for the NCl-60 cancer cell panel. Mol Cancer Therapeut 2007, 6:|483-|49|.

59. NCl-60 Expression Data [http://dtp.nci.nih.gov/mtargets/down load.html]

60. Lall S, Grun D, Krek A, Chen K, Wang YL, Dewey CN, Sood P, Colombo T, Bray N, Macmenamin P, et al.: A genome-wide map of conserved microRNA targets in C. elegans. Curr Biol 2006, I6:460-47|,

61. RNA22 miRNA Target Predictions [http://cbc srv.watson.ibm.com/rna22 download.html]

62. Pruitt KD, Tatusova T, Maglott DR: NCBI reference sequences (RefSeq): a curated non-redundant sequence database of genomes, transcripts and proteins. Nucleic Acids Res 2007, 35:D6I-65.

63. Dennis G Jr, Sherman BT, Hosack DA, Yang J, Gao W, Lane HC, Lempicki RA: DAVID: Database for Annotation, Visualization, and Integrated Discovery. Genome Biol 2003, 4:P3.

64. Ashburner M, Ball CA, Blake JA, Botstein D, Butler H, Cherry JM, Davis AP, Dolinski K, Dwight SS, Eppig JT, et al.: Gene ontology: tool for the unification of biology. The Gene Ontology Consortium. Nat Genet 2000, 25:25-29. 